\title{
Current and emerging treatments for absence seizures in young patients
}

\author{
This article was published in the following Dove Press journal: \\ Neuropsychiatric Disease and Treatment \\ 10 July 2013 \\ Number of times this article has been viewed
}

\author{
Pascal Vrielynck \\ William Lennox Neurological Center, \\ Reference Centre for Refractory \\ Epilepsy, Catholic University of \\ Louvain, Belgium
}

\begin{abstract}
In this report, we review the pharmacological and non-pharmacological treatments of the different absence seizure types as recently recognized by the International League Against Epilepsy: typical absences, atypical absences, myoclonic absences, and eyelid myoclonia with absences. Overall, valproate and ethosuximide remain the principal anti-absence drugs. Typical absence seizures exhibit a specific electroclinical semiology, pathophysiology, and pharmacological response profile. A large-scale comparative study has recently confirmed the key role of ethosuximide in the treatment of childhood absence epilepsy, more than 50 years after its introduction. No new antiepileptic drug has proven major efficacy against typical absences. Of the medications under development, brivaracetam might be an efficacious anti-absence drug Some experimental drugs also show efficacy in animal models of typical absence seizures. The treatment of other absence seizure types is not supported with a high level of evidence. Rufinamide appears to be the most promising new antiepileptic drug for atypical absences and possibly for myoclonic absences. The efficacy of vagal nerve stimulation should be further evaluated for atypical absences. Levetiracetam appears to display a particular efficacy in eyelid myoclonia with absences. Finally, it is important to remember that the majority of antiepileptic drugs, whether they be old or new, may aggravate typical and atypical absence seizures.
\end{abstract}

Keywords: antiepileptic drug, typical absence, atypical absence, myoclonic absence, eyelid myoclonia with absence

\section{Introduction}

\section{Absence seizure types and syndromes}

Absences are types of epileptic seizure that are clinically characterized by a transitory alteration of consciousness, with or without other clinical signs, associated on electroencephalogram (EEG) with diffuse spike-and-wave discharges (SWD) of variable duration - usually between 3 and 30 seconds. ${ }^{1}$ Absences may occur at any age, but they mostly affect children and adolescents, representing about $10 \%$ of seizures in children. ${ }^{2}$

Absence seizures were clinically identified in the 17 th century, ${ }^{3}$ and their epileptic nature was demonstrated by the first ictal EEG recordings in $1934 .{ }^{4}$ In 1981 , the International League Against Epilepsy (ILAE) classed absences in the category of generalized seizures, and defined their electroclinical characteristics, differentiating typical and atypical absences. ${ }^{5}$

During typical absence seizures (TAS), the EEG shows generalized, regular, synchronous SWD with a frequency of more than $2.5 \mathrm{~Hz} .^{3,6}$ The alteration of consciousness is marked, and can be accompanied by automatisms if the episode is
Correspondence: Pascal Vrielynck Centre Neurologique William Lennox, Allée de Clerlande 6, I 340 Ottignies, Belgium

Tel +32 I0 430229

Fax +32 I0 430246

Email pascal.vrielynck@cnwl.be 
long (old concepts of simple and complex absences), and sometimes by slight myoclonus. . $^{3,6}$

During atypical absence seizures (AAS), the EEG shows diffuse, irregular SWD with a frequency of less than $2.5 \mathrm{~Hz}$. The alteration of consciousness is variable. The clinical manifestations are more subtle, and include a slowing-down of the ongoing activity, which is possibly accompanied by myoclonus and a slow loss of muscle tone.

In 2010, in its latest classification proposal, the ILAE recognized two additional absence types with specific features. ${ }^{7}$ In myoclonic absences, ictal EEG is similar to TAS, but seizures are accompanied by marked bilateral rhythmical clonic jerks. In eyelid myoclonia with absences, impairment of consciousness is mild and EEG shows rhythmic diffuse polyspike-wave discharges, usually at 5-6 Hz. ${ }^{1}$

Each absence type can be found in one or several epileptic syndromes, which were distinguished by the ILAE in $1989 .^{8}$

TAS occurs in idiopathic generalized epilepsies, affecting patients with normal psychomotor development, and normal cerebral imaging and background EEG activity. ${ }^{3}$ In childhood absence epilepsy, absences are the only seizure type, occurring between 2 and 12 years of age and disappearing in the majority of cases at the beginning of adolescence. In juvenile absence epilepsy, the absences, which are the predominant type of seizure, are frequently accompanied by tonic-clonic seizures. ${ }^{3}$ TAS can also occur in juvenile myoclonic epilepsy, accompanied by myoclonic seizures and tonic-clonic seizures. ${ }^{3}$

AAS occurs in children and adults, mostly as part of epileptic encephalopathies, accompanied by retardation in psychomotor development, which is considered to be at least partly the consequence of the epileptic activity. ${ }^{1}$ AAS are usually not the only seizure type. These conditions include Lennox-Gastaut syndrome (LGS), continuous SWD during sleep syndrome, epilepsy with myoclonic-astatic seizures, and Dravet syndrome. ${ }^{1}$

The absences with special features are each linked to a specific epileptic syndrome that associates common ages of onset, prognosis, and electroclinical data, such as epilepsy with myoclonic absences and eyelid myoclonia with absences. ${ }^{9,10}$

\section{Pathophysiology}

TAS have been most studied. Our knowledge comes from neurophysiological studies and functional imaging carried out on humans, and from data obtained in animal experiments.
During TAS recorded in humans by combined EEG and functional magnetic resonance imaging (EEG-fMRI), the bilateral symmetrical activation of the thalamus is constant. ${ }^{11}$ Certain cortical regions, which are variable from one patient to the next - but constant in each patient, are bilaterally activated - in particular the frontal-insular regions. ${ }^{11}$ Other cortical regions are deactivated, in particular those involved in the "default mode network", such as the parietal lobe and precuneus. ${ }^{11}$ This may account for the marked alteration of consciousness during absence seizures. ${ }^{11}$

Animal models enable us not only to better understand the pathophysiology of TAS, but also to test the anti-absence efficacy of new antiepileptic drugs (AED). ${ }^{6}$ The absences can be induced pharmacologically, for instance with $\gamma$-hydroxybutyrate (GHB), or they can occur spontaneously in mono- and polygenic genetic models. ${ }^{6}$ Examples include lethargic (lh/lh) mouse, which carries a mutation of the Cacnb4 gene that encodes a subunit of a voltage-dependent calcium channel, as well as the two main polygenic models: Wistar Albino Rats from Rijswijk (Wag/Rij) and Genetic Absence Epilepsy Rats from Strasbourg (GAERS). These two models are used the most, because their behavioral, electrophysiological, and pharmacological characteristics resemble TAS in humans. ${ }^{12}$ The majority of anti-absence medications that are efficacious in humans are also efficacious in these models. ${ }^{12}$

According to these animal studies, TAS results from the abnormal cyclic activation of a bilateral anatomic network that comprises three structures: certain cortical regions, thalamic relay nuclei, and thalamic reticular nuclei. ${ }^{1}$ This cycle is probably initiated in the cortex. ${ }^{1}$ The SWD recorded by scalp EEG correspond to the regular oscillatory activation of these corticothalamocortical loops, the spike corresponding to synchronous excitatory neuronal activity, and the slow wave to neuronal inactivation. ${ }^{1}$ This cycle involves reciprocal excitatory glutamatergic connections between the thalamus and cortex, and inhibitory GABAergic influence of the thalamic reticular nuclei on the thalamic relay nuclei. ${ }^{1}$ Low-threshold (T-type) voltage-dependent calcium channels in the thalamocortical neurons are activated in an oscillatory way by this GABA-induced hyperpolarization. Activity of hyperpolarization-activated cyclic nucleotidegated $(\mathrm{HCN})$ channels, dopaminergic influence from the basal nuclei, and inflammatory processes also contribute to regulate oscillatory thalamocortical activity. ${ }^{13-15}$

The involvement of low-threshold calcium channels, $\mathrm{HCN}$ channels, $\mathrm{GABA}_{\mathrm{A}}$ and $\mathrm{GABA}_{\mathrm{B}}$ receptors, glutamate and dopamine receptors, and inflammatory processes are all potential therapeutic targets in the treatment of TAS. ${ }^{1,12}$ 
The pathophysiology of AAS is less well-known. Two animal models have recently been proposed: a pharmacological model comprising the administration of AY-9944, an inhibitor of 7-dehydrocholesterol reductase, to a rat or mouse, and a genetic model, the transgenic mouse $\mathrm{GABA}_{\mathrm{B}} \mathrm{R} 1 \mathrm{a}^{\mathrm{tg}}$, in which a subunit of the $\mathrm{GABA}_{\mathrm{B}}$ receptor is over-expressed. ${ }^{6}$ These animal models display impaired learning, lower hippocampal synaptic plasticity, and atypical absences involving the hippocampus as well as the thalamocortical loops. ${ }^{6}$ The involvement of the hippocampal regions may account for the associated cognitive difficulties. ${ }^{6}$ The usefulness of these models for evaluating antiepileptic medication efficacy has not been clearly established.

\section{Treatment of typical absences Goals of treatment}

TAS occurs in children and adolescents of normal intelligence. ${ }^{3}$ The prognosis for childhood absence epilepsy is favorable, because the seizures spontaneously disappear after an average period of 6-7 years. ${ }^{16}$ What is more, the repetition of epileptic absences, even during status epilepticus, does not seem to provoke any neuronal lesions. ${ }^{17}$ Despite these reassuring factors, having this seizure type has negative effects on children's lives:

- academic performance is lowered $;^{18}$

- accident risks are increased, for example while cycling; ${ }^{19}$

- interictal attention disorders have been observed, which seem to be unrelated to seizure frequency; ${ }^{20,21}$

- anxiety-depression and behavioral disorders are more common than in the general population. ${ }^{22}$

Lowering seizure frequency is the main evaluation criterion in the clinical studies that have been published. ${ }^{23}$ This objective makes it possible, of course, to reduce accident risk and embarrassment that the seizures cause directly. However, the treatment's impact on cognitivebehavioral disorders and quality of life has rarely been studied. Attention disorders seem to persist despite the lowered seizure frequency. ${ }^{23}$ Concerning the evolution of depressive effects, studies on animal models have yielded contradictory results. ${ }^{24}$

It is interesting to note that an "antiepileptogenic" effect of some anti-absence medications, in particular ethosuximide (ESM), has been proven in animals. Indeed, when administered early in life to WAG/Rij (Wistar Albino Glaxo from Rijswijk) rats, this medication retards and lowers epileptic activity on a long-term basis, after treatment discontinuation. ${ }^{25}$ In humans, the treatment's influence on long-term prognosis is not known. Bergamini et al suggested that patient prognosis was better if the early treatment was well-adapted and efficacious. ${ }^{26}$

In practice, treatment is aimed to lower seizure frequency as much as possible without causing any undesired effects, in particular in terms of cognition and behavior. Monotherapy is therefore recommended in the majority of cases. Treatment duration is restricted in children, as the absences disappear spontaneously after a few years, at least in the "pure" childhood absence epilepsy syndrome. ${ }^{2}$ Treatment may be stopped after 1 or 2 years of being seizure-free if the EEG has normalized. ${ }^{3}$

\section{First-line medications}

ESM, valproate (VPA), and lamotrigine (LTG) are the three first-line AED mentioned in the main guidelines published recently. ${ }^{27,28}$ The majority of studies that evaluated their efficacy in this indication have their limitations. Those published prior to the publication of the international classification of epileptic syndromes included non-homogeneous groups. The evaluation of seizures is often only clinical, which underestimated their true seizure frequency. Recently, however, an important, well-conducted, large-scale study allowed for a better understanding of the usefulness of these three drugs.

\section{Ethosuximide}

ESM is one of the oldest anti-absence medications, after trimethadione, which is no longer used because of its toxicity. The drug proved efficacious in the main animal models, in particular GAERS and Wag/Rij. ${ }^{12}$ ESM's main mechanism of action is the blockage of T-type voltage-dependent calcium channels, which would account for its action against thalamocortical hyperexcitability. ${ }^{29}$

The drug's clinical efficacy against absences was put forward in the first clinical publication, which reported a $66 \%$ response rate (seizure-frequency reduction $>80 \%$ ) in a population of 109 patients. ${ }^{30}$ Furthermore, $61 \%$ of patients with "pure absences" were seizure-free. Recent retrospective data on large cohorts confirmed a high rate of freedom from seizures, ranging from $85 \%-90 \% .^{31,32}$ One prospective study including a placebo phase was published, but the study was not randomized. ${ }^{33}$ After a 1 -week placebo run-in phase, 37 newly diagnosed children were treated with ESM. The mean response rate was 95\% (seizure-frequency reduction $>50 \%$ ), but the population was not homogeneous, for 14 children exhibited other seizure types. ${ }^{2}$

ESM is generally well tolerated. Most common adverse effects are related to the digestive system. ${ }^{2}$ For this reason, 
it is recommended that the daily dose be divided into at least two doses, which should be taken at mealtimes. ${ }^{2}$ Rare but severe adverse effects may occur, such as aplastic anemia and cutaneous allergic reactions. ${ }^{2}$ There are no published cases on ESM-induced absences aggravation. ESM's main disadvantage is the drug's ineffectiveness against other seizures types, in particular tonic-clonic seizures. ${ }^{2}$

\section{Valproate}

From the beginning of its clinical use, VPA was noted for its particular efficacy against generalized seizures. ${ }^{34} \mathrm{VPA}$ is currently the treatment of choice for idiopathic generalized epilepsies. ${ }^{35}$ The drug proved efficacious in animal absence models. ${ }^{12}$ VPA's supposed mechanisms of action are numerous: blockage of voltage-dependent sodium channels and L-type calcium channels, and increases in intracerebral GABA levels. ${ }^{36}$ Its action on calcium channels may account for its anti-absence efficacy. ${ }^{36}$

Recent retrospective data confirmed high rates of freedom from seizure, ranging from $77 \%-85 \% .^{31,32}$ Besides the disappearance of clinical absences, frequency and duration of generalized SWD were significantly reduced in more than $80 \%$ of cases. ${ }^{37}$ One placebo-controlled study has been published, but it was not randomized and included children with refractory absences as well as other seizure types. ${ }^{38}$ After a 2-week placebo run-in period, 17 children were treated with VPA for 10 weeks. The mean response rate was $82 \%$ (seizure-frequency reduction $>75 \%$ ), and $59 \%$ of cases were seizure-free. $^{38}$

VPA is not always well tolerated in children, and may cause attention disorders, weight gain, tiredness, and agitation. The potentially serious risk of fulminant hepatitis is low in children over 2 years of age, undergoing VPA monotherapy. ${ }^{2}$

Cases of VPA-induced TAS aggravation have been reported. These reports are rare but well-documented. ${ }^{39}$

\section{Lamotrigine}

LTG is a broad-spectrum AED, introduced in 1993, and initially used in symptomatic focal epilepsies. In 1995, a first retrospective study showed its utility in the treatment of absences. ${ }^{40}$ LTG is not efficacious in the standard animal models, ie, GAERS and Wag/Rij, but does have an effect in the lethargic mouse model. ${ }^{41}$ Its principal mechanism of action is the blockage of voltage-dependent sodium channels. ${ }^{36}$ However, this molecule has a spectrum of activity larger than the other "classical" sodium channel blockers, such as carbamazepine (CBZ). ${ }^{36}$ Recently, another mechanism was suggested, namely an effect on the HCN channel, which could explain its efficacy on absences. ${ }^{13}$

The initial prospective studies were encouraging, with seizure-free rates of $55 \%$ in a series of 20 children, and $56 \%$ in a series of 54 children. ${ }^{42,43}$ A double-blind, placebocontrolled study of low magnitude, evaluating 29 children, showed that LTG was more efficacious than placebo, with a seizure-free rate of $64 \%$ in the LTG group versus $21 \%$ in the placebo group. ${ }^{44}$ On the other hand, the association of VPA with low-dose LTG showed, in several publications, good efficacy for refractory absences..$^{40,45,46}$

LTG is well tolerated from the cognitive perspective and does not have sedative effects. ${ }^{2}$ The principal disadvantage is the risk of cutaneous allergic reactions, some of which are serious which requires a long dose titration in order to reduce the risk. ${ }^{2}$ Aggravation of absences under LTG has not been reported.

\section{Randomized prospective comparative studies Valproate versus ethosuximide}

Two prospective, randomized studies showed a comparable seizure-free rate between the ESM and VPA groups treated for newly diagnosed absence epilepsy, $85 \%$ versus $86 \%$ and $80 \%$ versus $70 \% .{ }^{47,48}$ The number of patients included in these studies was low: 28 children and adolescents for the first and 20 children for the second. A third double-blind study evaluating a non-homogeneous population of 45 patients did not show a statistically significant difference between the ESM and VPA groups. ${ }^{49}$

\section{Valproate versus lamotrigine}

A double-blind prospective study evaluated 38 newly diagnosed patients randomized into two groups and treated with VPA or LTG. ${ }^{50}$ The seizure-free rate after 3 months and 1 year was $63 \%$ and $68 \%$ for VPA versus $37 \%$ and $53 \%$ for LTG, respectively, the differences between the groups being not significant.

\section{Valproate versus lamotrigine versus ethosuximide}

Recently, an important prospective, randomized, doubleblind, multicenter study including 453 patients presenting childhood absence epilepsy was published. ${ }^{23,51}$ The primary outcome was to evaluate the number of seizure-free patients without side-effects in the medium-term (16-20 weeks) and in the long-term (1 year). The patients were considered seizure-free if no absence was observed by the family, in the hyperventilation test, and the video-EEG recording during 1 hour. VPA and ESM appeared to be more effective than 
LTG at 16-20 weeks (retention rate, respectively 58\%, 53\%, and $29 \%$ ) and at 1 year $(44 \%, 45 \%$, and $21 \%)$. The dose of VPA at 16-20 weeks was $34.9 \pm 16 \mathrm{mg} / \mathrm{kg} /$ day, ESM was $33.5 \pm 15 \mathrm{mg} / \mathrm{kg} / \mathrm{day}$; and LTG was $9.7 \pm 6 \mathrm{mg} / \mathrm{kg} /$ day. There was no difference in tolerance at 16-20 weeks between VPA, ESM, and LTG. At 1 year, VPA was tolerated less than ESM and LTG, notably due to weight gain $(8 \%$ of VPA patients discontinued the study for this reason). The secondary outcome was to evaluate attention dysfunction using a test called "continuous performance test". Attention difficulties were significantly increased in the VPA group as compared to the other two groups at medium- and longterm.

\section{Summary}

LTG is more efficacious than placebo. ESM and VPA have a similar efficacy, which is greater than that of LTG. ESM and LTG are better tolerated than VPA in the long-term and cause less attention dysfunction. Thus, VPA and ESM remain the principal anti-absence drugs. ESM appears to be the treatment of choice for childhood absence epilepsy on account of its good tolerability. In juvenile absence epilepsy, VPA is preferable to ESM as first-line therapy, because of the risk of associated tonic-clonic seizures.

\section{Medications that could be of use as a second- or third-line therapy Benzodiazepines}

While the majority of GABAergic medications have a paradoxal activating action on the thalamocortical loop and may aggravate TAS, the benzodiazepines and $\mathrm{GABA}_{\mathrm{A}}$ receptor agonists exhibit a beneficial action, whether it is in humans or in animal models. According to Weiergräber et al, they act preferentially on the neurons in the thalamic reticular nucleus by "desynchronizing" their oscillatory influence on the thalamocortical loops. ${ }^{1}$

Clobazam (CLB) and clonazepam (CNZ) are the two main benzodiazepines used in association in the chronic treatment of refractory epilepsies. They both have the risk of dependence and habituation and cause side-effects including somnolence, ataxia, or hyperactivity.

The efficacy of CLB on absences has not been studied prospectively. In a large retrospective Canadian study, improvement was reported in a subgroup of 53 patients with TAS. ${ }^{52}$

A prospective, crossover study versus placebo evaluated 10 patients with refractory absences during an 8-week period. ${ }^{33}$ Eight patients were seizure-free with 3-6 mg of CNZ.
The primary side-effect was sedation. A double-blind study compared CNZ and ESM in 79 children during 17 weeks. ${ }^{54}$ The retention rate was higher in the ESM group: 91.7\% versus $69.8 \%$. Somnolence, hyperactivity, and habituation were the causes of study discontinuation in the CNZ group.

\section{Summary}

The chronic efficacy of benzodiazepines has not been sufficiently evaluated in this indication.

\section{Levetiracetam}

Levetiracetam (LEV), whose anti-epileptic activity is accounted for by its action on the synaptic vesicle protein SV2A, has demonstrated its efficacy in GAERS and Wag/ Rij animal models of absences. ${ }^{36}$ An initial open-label, prospective study showed encouraging results. ${ }^{55}$ In a group of 21 newly diagnosed children and adolescents treated with LEV during 6 months, 11 were seizure-free at a maximum dose of $70 \mathrm{mg} / \mathrm{kg} /$ day. The evaluation was based on clinical assessment and EEG recordings.

Recently, a multicenter study evaluated the LEV efficacy on TAS in a double-blind manner versus placebo during a period of only 2 weeks. ${ }^{56}$ Among the 59 newly diagnosed children and adolescents included, $23.7 \%$ were seizure-free, clinically and on EEG recordings, in LEV group, versus $4.8 \%$ in placebo group. LEV was well tolerated. The doses were relatively low, maximally at $30 \mathrm{mg} / \mathrm{kg} /$ day. However, during the study's extension phase, the majority of LEV-nonresponders, even at higher doses, exhibited seizure-freedom after VPA or ESM administration.

Finally, cases of TAS aggravation following LEV administration have been described. ${ }^{57}$

\section{Summary}

While promising in animal models, LEV appears to exhibit only modest clinical efficacy in TAS.

\section{Topiramate and zonisamide}

Topiramate (TPM) and zonisamide (ZNS) are broad-spectrum AED, possessing multiple common mechanisms of action: carbonic anhydrase inhibition, sodium channel blockage, and GABAergic activity. In addition, TPM is an AMPA receptor antagonist, and ZNS has calcium channel blockage activity. ${ }^{36}$ These drugs proved efficacious in animal absence models. No randomized study evaluating their clinical effectiveness is available.

Two open monotherapy studies evaluating TPM in TAS have been published, involving a limited number of patients. 
Among five children, some of them with refractory absence epilepsy, one became seizure-free, two were improved, and two unchanged following 6 weeks of therapy with TPM. ${ }^{58}$ Recently, a prospective study including 12 newly-diagnosed children was discontinued prematurely due to lack of efficacy. ${ }^{59}$ Only two patients became clinically seizure-free but with persistent EEG seizures.

ZNS's efficacy on TAS is suggested by retrospective data. In a small series of eight patients, $50 \%$ were seizure-free. ${ }^{60}$ In a larger series, ZNS was administered in association to 45 patients with typical and atypical absences, and $51 \%$ of patients became clinically seizure-free, but without EEG evaluation. ${ }^{61}$

No cases of aggravation of TAS by TPM or ZNS have been published.

\section{Summary}

There is insufficient proof of the clinical efficacy of TPM and ZNS in TAS. These compounds should thus be limited to refractory cases.

\section{Amantadine and acetazolamide}

The efficacy of amantadine, an antiviral medication, on TAS may be accounted for by its dopaminergic action. ${ }^{62}$ Two retrospective studies suggested a usefulness of amantadine in the treatment of refractory TAS. Shahar et al reported on four children who were seizure-free during 24-36 months. ${ }^{63}$ Recently, among a series of 13 patients refractory to standard therapies, eight were considered responders at 3 months (decrease in seizure frequency $>50 \%$ ). ${ }^{62}$ The evaluation was solely based on clinical assessments.

Acetazolamide (ACZ), a carbonic anhydrase inhibitor, is efficacious in animal models of absences. ${ }^{13}$ The drug's efficacy could be explained by it action on the HCN channel. ${ }^{13}$ Two old studies showed a certain degree of clinical benefit, but ACZ's efficacy appears to decrease over the long-term. The responder rates (decrease of $>80 \%$ in seizure frequency) were $48 \%$ and $71 \%$, respectively. ${ }^{64,65}$

\section{Summary}

The scientific data is weak. These molecules should be reserved for refractory cases.

\section{Medications potentially causing aggravation}

While reported for all types of seizures, aggravation of epilepsy caused by AED principally concerns generalized seizures. True frequency of this phenomenon is discussed. ${ }^{66,67}$
No prospective study has examined this topic. Data is derived from clinical cases and animal experiments. In addition to a specific effect directly related to certain AED, a nonspecific phenomenon of absence aggravation due to anti-epileptic drug-induced somnolence can also be encountered, notably in cases of drug overdose.

\section{Carbamazepine and oxcarbazepine}

The aggravation of TAS by CBZ and oxcarbazepine (OXC) has been well documented in the GAERS and Wag/Rij rat models. In contrast to what was initially thought, absence aggravation caused by $\mathrm{CBZ}$ and $\mathrm{OXC}$ does not likely relate to their action on sodium channels, but rather to $\mathrm{GABA}$ receptor activation at the thalamocortical level. ${ }^{68,69}$ In the absence of prospective data, the clinical incidence of TAS aggravation is unknown. Cases of aggravation of pre-existing absences, induction of de novo absences or generalized SWD have been reported retrospectively. ${ }^{70-72}$

\section{Vigabatrin and tiagabine}

Vigabatrin (VGB) and tiagabine (TGB) are GABAergic molecules, with potential "pro-absence" activity. They act via irreversible GABA transaminase enzyme inhibition and selective GABA recapture inhibition, respectively. ${ }^{36}$ In animal models, aggravation is accounted for by GABAergic reinforcement at the thalamic level, which paradoxically leads to increased excitability of the thalamocortical loops. ${ }^{73,74}$ Clinically, VGB and TGB can aggravate TAS and, at times, induce de novo absences. ${ }^{75-79}$ On the other hand, several cases of induced non-convulsive status have been reported following TGB introduction, even in non-epileptic patients. ${ }^{80-82}$

\section{Phenytoin and phenobarbital}

These two molecules can cause absence aggravation in animal models. ${ }^{12}$ Clinically, cases of TAS aggravation by phenytoin (PHT) or phenobarbital (PB) have been reported more rarely than for the four preceding drugs. ${ }^{66,83}$ The induction of absence status by PHT has been reported. ${ }^{84}$ PB might have a beneficial effect at low doses and cause aggravation at high doses. ${ }^{83}$

\section{Probably ineffective drugs}

In animal models, gabapentin (GBP), pregabalin, lacosamide, perampanel, and retigabine were shown to be ineffective. ${ }^{83-85}$ Clinical data regarding the last four AED are not yet available. 
With respect to GBP, a prospective placebo-controlled study involving 33 children with absence epilepsy was conducted over a 2 -week period, with no statistically significant difference found between the two groups. ${ }^{88}$ No deterioration in patients was observed, with relatively low GBP doses used, namely $15-20 \mathrm{mg} / \mathrm{kg}$.

\section{Non-pharmacological methods Ketogenic diet}

The ketogenic diet (KD) is currently indicated mainly for intractable epilepsy patients, especially those with epileptic encephalopathy. KD is the treatment of choice for epileptic patients with GLUT-1 deficiency. SCL2A1 mutation has been observed in a small fraction of patients with early-onset typical absences. ${ }^{89} \mathrm{KD}$ is not effective in animal GAERS model. ${ }^{90}$

Groomes et al conducted a meta-analysis of 17 trials involving 133 TAS patients. ${ }^{91}$ Most studies are old; published before the commercialization of effective anti-absence drugs. Overall, mean response rate (decrease in seizure frequency $>50 \%$ ) was $69 \%$, with $34 \%$ seizure free. In the retrospective series of Groomes et al involving 21 patients, $82 \%$ were responders and $19 \%$ seizure free. The publication did not mention whether patients with GLUT-1 deficiency were included in these studies.

\section{Vagal nerve stimulation}

In GAERS rats, acute vagal nerve stimulation (VNS) was associated with an increase in SWD duration, whereas chronic stimulation over 5 days had no effect. ${ }^{92}$

The clinical effectiveness of VNS in TAS patients is not well-known. In a small, prospective series involving 12 child and adult patients with idiopathic generalized epilepsy, a $58 \%$ reduction in absence frequency was reported. ${ }^{93}$ Recently, nine patients with refractory TAS treated with VNS were retrospectively reviewed. A 53\% reduction in seizure frequency was found. ${ }^{94}$

\section{Drugs under development/ experimental drugs}

Of the AED under development, brivaracetam (BRV), a novel SV2A ligand, displayed a higher anti-absence activity in GAERS rats, in comparison with LEV. ${ }^{86} \mathrm{BRV}$ was clinically tested prospectively in a population of 49 adult patients with refractory idiopathic generalized epilepsy, 18 of which presented absences. ${ }^{95}$ Overall, $44.4 \%$ of patients responded to BRV versus $15.4 \%$ to placebo. The percentage of patients that exhibited an absence reduction was not mentioned.
Several experimental drugs have shown efficacy in animal absence epilepsy models, but have not been clinically evaluated:

- Rapamycin is an mTOR inhibitor that displays modulatory activity on cerebral inflammation. ${ }^{15}$ Everolimus, a rapamycin-derivative, has been recently approved as therapy for subependymal giant-cell astrocytomas in tuberous sclerosis. According to a recent publication, rapamycin exerted sustained antiepileptogenic effect, in addition to direct antiepileptic effects in the Wag/Rij rat absence epilepsy model. ${ }^{15}$

- The $\mathrm{GABA}_{\mathrm{B}}$ receptor antagonists are effective in animal models of typical and atypical absence seizures. ${ }^{96}$

- Several substances that modulate glutamate metabotropic receptors are presently undergoing clinical evaluation for neurological or psychiatric diseases, such as anxiety disorders, Parkinson's disease, and schizophrenia. Some of these agents exhibited encouraging results in animal models of absence epilepsy. ${ }^{97}$

- Lastly, two new compounds, Z941 and Z944, specifically block T-type calcium channels responsible for highfrequency neuron firing. In GAERS rats, these two compounds showed significant anti-absence activity. ${ }^{98}$

\section{Treatment of other absence seizure types Atypical absences}

Atypical absence seizures (AAS) are often considered minor seizures, for they are neither accompanied by brutal falls, nor are they directly life-threatening. However, they likely contribute to the learning disabilities associated with epileptic encephalopathies. ${ }^{99}$ Particularly in the LennoxGastaut syndrome, cognitive regression or stagnation may be accounted for by a dysfunction in normal brain maturation, due to numerous slow and diffuse SWD, which occur during and between seizures, even if AAS could not directly cause neuronal lesions..$^{100,101}$

Though not proven, the control of AAS might diminish their negative impact on cognitive development. Nevertheless, animal experiments to determine the impact of AAS control on cognitive development did not provide any clear answers. ${ }^{102,103}$

Most related review articles indicate that AAS would display the same pharmacological response profile as TAS. ${ }^{104,105}$ This assertion, however, has not yet been proven by prospective randomized trials. Currently, there is little evidence-based data to guide the effective management of AAS. These seizures are difficult to recognize at the clinical 
Table I Summary of AED efficacy in different absence seizure types

\begin{tabular}{|c|c|c|c|c|c|c|}
\hline & TAS & AAS & EMA & MA & Main advantage & Main disadvantage \\
\hline Valproate & +++ & ++ & ++ & ++ & $\begin{array}{l}\text { Effective against all seizure } \\
\text { types }\end{array}$ & $\begin{array}{l}\text { Should be avoided in } \\
\text { girls of childbearing age }\end{array}$ \\
\hline Ethosuximide & +++ & ++ & $+?$ & ++ & Minimal cognitive side effects & $\begin{array}{l}\text { Ineffective against } \\
\text { tonic-clonic seizures }\end{array}$ \\
\hline Lamotrigine & ++ & + & $+?$ & $+?$ & Favorable tolerability profile & Long dose titration \\
\hline Levetiracetam & + & $?$ & ++ & $?$ & Favorable tolerability profile & \\
\hline Rufinamide & $?$ & ++ & $?$ & $++?$ & $\begin{array}{l}\text { Effective against drop-attacks } \\
\text { in LGS }\end{array}$ & Limited experience \\
\hline Benzodiazepine & ++ & $++(\mathrm{CLB})$ & $++(\mathrm{CNZ})$ & $?$ & Rapidly effective & $\begin{array}{l}\text { Risk of dependence } \\
\text { and habituation }\end{array}$ \\
\hline
\end{tabular}

Notes: Degree of efficacy: +++ high, ++ moderate, + weak, ? unknown.

Abbreviations: TAS, typical absence seizures; AAS, atypical absence seizures; EMA, eyelid myoclonia with absences; MA, myoclonic absences; CLB, clobazam, CNZ, clonazepam; LGS, Lennox-Gastaut Syndrome; AED, antiepileptic drug.

level, and no studies using long-term EEG-video monitoring have specifically addressed this clinical condition.

The scarce available data is derived from prospective controlled studies evaluating the effectiveness of new AED on Lennox-Gastaut seizures. Since there was a high placebo response to this seizure type in LGS, data derived from open studies should be considered with caution. ${ }^{106,107}$

We shall now review the different AED with potential application in AAS management. VPA and ESM are classically the preferred treatments. ${ }^{108}$ This recommendation is based mainly on clinical experience, as well as on old retrospective series with non-homogeneous patient populations. ${ }^{109,110}$ In LGS, VPA is more frequently used than ESM, for it also protects against other seizure types. VPA was reported to decrease atypical absence frequency by approximately $25 \%-30 \% .{ }^{104}$ In Dravet syndrome, AAS seems to respond in a similar manner to VPA or ESM. ${ }^{111}$

Benzodiazepines may prove effective in controlling AAS, but the risk of sedation and dependence limits their use. A large Canadian study evaluating retrospectively CLB efficacy in the management of various epileptic syndromes involved 139 AAS patients. The majority of these patients were reported to be responders. ${ }^{52}$ In a recent randomized, placebocontrolled trial evaluating CLB efficacy in LGS, the treatment outcome on AAS was not reported. ${ }^{112}$ It must be noted that benzodiazepine administration might aggravate tonic seizures in Lennox-Gastaut syndrome patients, especially when administered via an intravenous route.

A certain degree of efficacy was observed with LTG in retrospective studies. ${ }^{113,114}$ However, in a randomized, placebo-controlled study of 16-week duration involving 169 patients with LGS, there was no statistically significant difference between groups with regard to AAS: a $13 \%$ decrease in atypical absence frequency was reported for the LTG group versus $38 \%$ for the placebo group. ${ }^{106} \mathrm{In}$ Dravet syndrome, atypical absences were not influenced by LTG treatment, but aggravation of other seizure types was reported in $80 \%$ of cases. ${ }^{115}$

In a randomized study of 11-week duration evaluating TPM in LGS, atypical absence frequency has not been clearly assessed. ${ }^{116}$

There is little data available on LEV. In a preliminary retrospective study, four patients exhibited a $25 \%-50 \%$ decrease in AAS frequency, whereas in a second study, six patients showed no improvement. ${ }^{117,118}$

Stiripentol, whose action mechanism is believed to be related to GABA binding, ${ }^{119}$ has been designated an orphan drug for use in Dravet syndrome. In a non-controlled trial, this compound was effective on AAS. ${ }^{120}$ After 20 weeks of treatment, absence frequency was diminished by $70 \%$. In a randomized, controlled study on Dravet syndrome patients, the drug's effect on AAS was not evaluated. ${ }^{119}$

Rufinamide is a new broad-spectrum AED, of which the mechanism of action is not fully understood. This drug is particularly effective for LGS. In a randomized, placebocontrolled study of 12 -week duration involving 139 patients, AAS frequency was decreased by $50.6 \%$ in the rufinamide group versus $29.8 \%$ in the placebo group. ${ }^{107}$

Felbamate is rarely used because of its hematological and hepatic toxicity. In LGS patients, the first retrospective studies showed a favorable effect on AAS. ${ }^{121}$ In a randomized placebo-controlled study, the drug's potential efficacy on AAS was not evaluated. ${ }^{122}$

ZNS may exert positive treatment effects according to several retrospective studies. ${ }^{59,60,123}$ In an uncontrolled, 
prospective study involving 27 children with AAS, 37\% were considered responders. ${ }^{124}$

CBZ and PHT may aggravate AAS. ${ }^{70,71,125}$ One case of AAS aggravation following GBP administration was also reported in Lennox-Gastaut syndrome. ${ }^{126}$

The effects of the ketogenic diet on LGS patients were retrospectively studied, but the diet's potential efficacy on AAS was not specifically investigated. ${ }^{127}$

VNS was shown to be effective on LGS, particularly with regard to seizures with brutal falls. Only two studies reported on AAS evolution post-VNS implantation, but assessments were based solely on retrospective clinical description. A multicenter study, which included 50 LGS patients, reported a $73 \%$ decrease in the frequency of AAS at 3 months and an $81 \%$ decrease at 6 months. ${ }^{128}$ Another retrospective study observed "good" AAS control in 46 LGS patients, while a decrease in the frequency of atypical absences was noted in three Dravet syndrome patients. ${ }^{129}$

\section{Summary}

AAS are more difficult to treat than TAS. Although evidencebased data is still lacking, VPA and ESM are thought to be effective. Clobazam might be useful. Rufinamide is the most promising new AED, as it proved effective against placebo in a double-blind trial. VNS may be an alternative therapeutic option.

\section{Eyelid myoclonia with absences}

Eyelid myoclonia with absence is difficult to treat, and tends to persist into adulthood. From a therapeutic perspective, this seizure type would more likely be considered a myoclonic seizure rather than a real absence. AED that are effective against photosensitivity should probably be favored.

Based on retrospective data, VPA, ESM, and benzodiazepines (especially CNZ) appear to be beneficial. In a retrospective series, $72 \%$ of patients were considered VPA responders. ${ }^{9}$ ESM should not be used in monotherapy because of the risk of associated tonic-clonic seizures. LTG may also be an effective treatment. ${ }^{130}$

In a prospective 12-week study evaluating the efficacy of LEV administered at a mean dose of $2000 \mathrm{mg} / \mathrm{day}$, $80 \%$ of the 35 study patients were responders, and $17 \%$ were seizure free. ${ }^{131}$

\section{Summary}

VPA and LEV both seem to be effective first-line treatments for the management of this syndrome.

\section{Myoclonic absences}

Because myoclonic absences are very rare, prospective studies have not been performed. Treatment recommendations are based on clinical experience and a few published case report series. Myoclonic absences are often resistant to antiepileptic therapy, and very few patients become seizure free with monotherapy. Therefore, polytherapy is required in most cases.

The combination of VPA and ESM, administered at high dose levels, is recommended by most authors. ${ }^{10,132}$ LTG add-on may prove useful. ${ }^{133} \mathrm{An}$ LEV-responsive case was reported. ${ }^{134}$ Recently, a report on three patients successfully treated with rufinamide was published. ${ }^{135}$ Of these patients, two became seizure free, and the third reported a $50 \%$ decrease in seizure frequency.

\section{Summary}

In addition to the standard VPA-ESM combination, rufinamide might be considered in the treatment of this rare syndrome.

\section{Conclusion}

Table one summarizes the AED efficacy in the four absence seizure types listed in the newly proposed ILAE epilepsy classification. Of these, only TAS has been the subject of large-scale randomized controlled trials. Based on these results, ESM seems to be the first-choice drug in the absence of other associated seizure types, namely in childhood absence epilepsy. In juvenile absence epilepsy, VPA is preferable to ESM as first-line therapy. Beyond their effects on seizure frequency, these drugs seem to not reduce interictal children's attention disorders, which are the main cognitive problems linked to absence epilepsy. Of the new drugs in development, brivaracetam and maybe rapamycin could become TAS treatment options in the future.

With regard to AAS, current data is very limited, and the choice of treatment is based mainly on clinical experience and expert recommendations. Specifically designed clinical studies are necessary, including an objective evaluation of seizure frequency and duration via long-term EEG-video monitoring. These studies should also assess whether the decreased absence frequency is accompanied by an improvement in associated cognitive and behavioral problems. Of the new AED, rufinamide appears to be the most promising. The effect of VNS seems interesting, but evidence-based data is missing.

Myoclonic absence management remains empirical. Rufinamide's potential efficacy must still be confirmed using prospective data. 
LEV, which exhibits modest efficacy on typical absences, appears to be with VPA a first-choice treatment in the management of eyelid myoclonia with absences, likely due to its anti-myoclonic activity.

\section{Disclosure}

The author reports no conflicts of interest in this work.

\section{References}

1. Weiergräber M, Stephani U, Köhling R. Voltage-gated calcium channels in the etiopathogenesis and treatment of absence epilepsy. Brain Res Rev. 2010;62:245-271.

2. Panayiotopoulos CP. Treatment of typical absence seizures and related epileptic syndromes. Paediatr Drugs. 2001;3:379-403.

3. Hirsch E, Thomas P, Panayiotopolos CP. Childhood and juvenile absence epilepsy. In: Engel J, Pedley TA, editors. Epilepsy: a comprehensive textbook. Second edition. Philadelphia: Lippincott Williams \& Wilkins; 2008:2397-2411.

4. Gibbs FA, Davis H, Lennox WG. The electroencephalogram in epilepsy and in conditions of impaired consciousness. Arch Neurol Psychiatry. 1935;34:1133-1148.

5. Commission on Classification and Terminology of the International League Against Epilepsy, 1981. Proposal for revised clinical and electroencephalographic classification of epileptic seizures. Epilepsia. 1981;22:489-501.

6. Onat FY, van Luijtelaar G, Nehlig A, Snead OC 3rd. The involvement of limbic structures in typical and atypical absence epilepsy. Epilepsy Res. 2013;103:111-123.

7. Berg AT, Berkovic SF, Brodie MJ, et al. Revised terminology and concepts for organization of seizures and epilepsies: report of the ILAE Commission on Classification and Terminology, 2005-2009. Epilepsia. 2010;5:676-685.

8. Commission on Classification and Terminology of the International League Against Epilepsy, 1989. Proposal for revised classification of epilepsies and epileptic syndromes. Epilepsia. 1989;30:389-399.

9. Covanis A. Eyelid myoclonia and absence. Adv Neurol. 2005;95: 185-196.

10. Bureau M, Tassinari CA. Epilepsy with myoclonic absences. Brain Dev. 2005;27:178-184

11. Gotman J, Pittau F. Combining EEG and fMRI in the study of epileptic discharges. Epilepsia. 2011;52(Suppl 4):S38-S42.

12. Manning JP, Richards DA, Bowery NG. Pharmacology of absence epilepsy. Trends Pharmacol Sci. 2003;24:542-529.

13. Poolos NP. Hyperpolarization-Activated Cyclic Nucleotide-Gated (HCN) Ion Channelopathy in Epilepsy. In: Noebels JL, Avoli M, Rogawski MA, Olsen RW, Delgado-Escueta AV, editors. Jasper's Basic Mechanisms of the Epilepsies [Internet]. 4th edition. Bethesda (MD): National Center for Biotechnology Information (US); 2012.

14. Deransart C, Riban V, Lê B, Marescaux C, Depaulis A. Dopamine in the striatum modulates seizures in a genetic model of absence epilepsy in the rat. Neuroscience. 2000;100:335-344.

15. Russo E, Citraro R, Donato G, et al. mTOR inhibition modulates epileptogenesis, seizures and depressive behavior in a genetic rat model of absence epilepsy. Neuropharmacology. 2013;69: 25-36.

16. Currier RD, Kooi KA, Saidman LJ. Prognosis of "pure" petit mal; a follow-up study. Neurology. 1963;13:959-967.

17. Shorvon S, Walker M. Status epilepticus in idiopathic generalized epilepsy. Epilepsia. 2005;46(Suppl 9):S73-S79.

18. Wirrell EC, Camfield CS, Camfield PR, Dooley JM, Gordon KE, Smith B. Long-term psychosocial outcome in typical absence epilepsy. Sometimes a wolf in sheeps' clothing. Arch Pediatr Adolesc Med. 1997;151:152-158.
19. Wirrell EC, Camfield PR, Camfield CS, Dooley JM, Gordon KE. Accidental injury is a serious risk in children with typical absence epilepsy. Arch Neurol. 1996;53:929-932.

20. Mirsky M, Primaca D, Marsana C, Rosvolda H, Stevens J. A comparison of the psychological test performance of patients with focal and nonfocal epilepsy. Exp Neurol. 1960;2:75-89.

21. Killory BD, Bai X, Negishi M, et al. Impaired attention and network connectivity in childhood absence epilepsy. Neuroimage. 2011;56: 2209-2217.

22. Vega C, Guo J, Killory B, et al. Symptoms of anxiety and depression in childhood absence epilepsy. Epilepsia. 2011;52:70-74.

23. Glauser TA, Cnaan A, Shinnar S, et al; for the Childhood Absence Epilepsy Study Team. Ethosuximide, valproic acid, and lamotrigine in childhood absence epilepsy: Initial monotherapy outcomes at 12 months. Epilepsia. 2013;54:141-155.

24. van Luijtelaar G. The prevention of behavioral consequences of idiopathic generalized epilepsy: evidence from rodent models. Neurosci Lett. 2011;497:177-184.

25. Russo E, Citraro R, Scicchitano F, et al. Comparison of the antiepileptogenic effects of an early long-term treatment with ethosuximide or levetiracetam in a genetic animal model of absence epilepsy. Epilepsia. 2010;51:1560-1569.

26. Bergamini L, Bram S, Broglia S, Riccio A. L'insorgenza tardiva di crisi Grande Male nel Piccolo Male. Studio catamnestico di 78 casi. [Late onset grand mal seizures in pure petit mal epilepsy]. Arch Suisses Neurol Neurochir Psychiatr. 1965;96:306-317. Italian.

27. Glauser T, Ben-Menachem E, Bourgeois B, et al. ILAE treatment guidelines: evidence-based analysis of antiepileptic drug efficacy and effectiveness as initial monotherapy for epileptic seizures and syndromes. Epilepsia. 2006;47:1094-1120.

28. Nunes VD, Sawyer L, Neilson J, Sarri G, Cross JH. Diagnosis and management of the epilepsies in adults and children: summary of updated NICE guidance. BMJ. 2012;344:e281.

29. Coulter DA, Huguenard JR, Prince DA. Specific petit mal anticonvulsants reduce calcium currents in thalamic neurons. Neurosci Lett. 1989;98:74-78.

30. Zimmerman FT, Burgemeister BB. A new drug for petit mal epilepsy. Neurology. 1958;8:769-775.

31. Covanis A, Skiadas K, Loli N, Lada C, Theodorou V. Absence epilepsy: early prognostic signs. Seizure. 1992;1:281-289.

32. Hwang H, Kim H, Kim SH, et al. Long-term effectiveness of ethosuximide, valproic acid, and lamotrigine in childhood absence epilepsy. Brain Dev. 2012;34:344-348.

33. Browne TR, Dreifuss FE, Dyken PR, et al. Ethosuximide in the treatment of absence (petit mal) seizures. Neurology. 1975;25:515-524.

34. Carraz G, Fau R, Chateau R, et al. Communication à propos des pemiers essais cliniques sur l'activité antiépileptique de l'acide n-dipropylacétique (sel de $\mathrm{Na}$ ) [Communication about first clinical trials of n-dipropylacetic acid (Na salt) antiepileptic activity]. Ann Med Psychol. (Paris). 1964;122: 577-585. French.

35. Marson AG, Al-Kharusi AM, Alwaidh M, PR; SANAD Study group. SANAD study of effectiveness of valproate, lamotrigine, or topiramate for generalised and unclassifiable epilepsy: an unblinded randomised controlled trial. Lancet. 2007;369:1016-1026.

36. White HS, Rho JM, editors. Mechanisms of Action of Antiepileptic Drugs. West Islip, New York: Professional Communications, Inc; 2010.

37. Villarreal HJ, Wilder BJ, Willmore LJ, Bauman AW, Hammond EJ, Bruni J. Effect of valproic acid on spike and wave discharges in patients with absence seizures. Neurology. 1978;28:886-891.

38. Erenberg G, Rothner AD, Henry CE, Cruse RP. Valproic acid in the treatment of intractable absence seizures in children: a single-blind clinical and quantitative EEG study. Am J Dis Child. 1982;136:526-529.

39. Lerman-Sagie T, Watemberg N, Kramer U, Shahar E, Lerman P. Absence seizures aggravated by valproic acid. Epilepsia. 2001;42:941-943.

40. Ferrie CD, Robinson RO, Knott C, Panayiotopoulos CP. Lamotrigine as an add-on drug in typical absence seizures. Acta Neurol Scand. 1995;91:200-202. 
41. Hosford DA, Wang Y. Utility of the lethargic (lh/lh) mouse model of absence seizures in predicting the effects of lamotrigine, vigabatrin, tiagabine, gabapentin, and topiramate against human absence seizures. Epilepsia. 1997;38:408-414.

42. Coppola G, Licciardi F, Sciscio N, Russo F, Carotenuto M, Pascotto A. Lamotrigine as first-line drug in childhood absence epilepsy: a clinical and neurophysiological study. Brain Dev. 2004;26:26-29.

43. Holmes GL, Frank LM, Sheth RD, et al. Lamotrigine monotherapy for newly diagnosed typical absence seizures in children. Epilepsy Res. 2008;82:124-132.

44. Frank LM, Enlow T, Holmes GL, et al. Lamictal (lamotrigine) monotherapy for typical absence seizures in children. Epilepsia. 1999;40:973-979.

45. Gericke CA, Picard F, de Saint-Martin A, Strumia S, Marescaux C, Hirsch E. Efficacy of lamotrigine in idiopathic generalized epilepsy syndromes: a video-EEG-controlled, open study. Epileptic Disord. 1999;1:159-165.

46. Buoni S, Grosso S, Fois A. Lamotrigine in typical absence epilepsy. Brain Dev. 1999;21:303-306.

47. Callaghan N, O'Hare J, O’Driscoll D, O’Neill B, Daly M. Comparative study of ethosuximide and sodium valproate in the treatment of typical absence seizures (petit mal). Dev Med Child Neurol. 1982;24:830-836.

48. Martinovic Z. Comparison of ethosuximide with sodium valproate as monotherapies of absence seizures. In: Parsonage M, et al. Advances in Epileptology: 14th Epilepsy International Symposium. New York Raven Press; 1983:301-305.

49. Sato S, White BG, Penry JK, Dreifuss FE, Sackellares JC, Kupferberg HJ. Valproic acid versus ethosuximide in the treatment of absence seizures. Neurology. 1982;32:157-163.

50. Coppola G, Auricchio G, Federico R, Carotenuto M, Pascotto A Lamotrigine versus valproic acid as first-line monotherapy in newly diagnosed typical absence seizures: an open-label, randomized, parallelgroup study. Epilepsia. 2004;45:1049-1053.

51. Glauser TA, Cnaan A, Shinnar S, et al; Childhood Absence Epilepsy Study Group. Ethosuximide, valproic acid, and lamotrigine in childhood absence epilepsy. N Engl J Med. 2010;362:790-799.

52. Canadian Clobazam Cooperative Group. Clobazam in treatment of refractory epilepsy: the Canadian experience. A retrospective study. Epilepsia. 1991;32:407-416.

53. Mikkelsen B, Birket-Smith E, Bradt S, et al. Clonazepam in the treatment of epilepsy. A controlled clinical trial in simple absences, bilateral massive epileptic myoclonus, and atonic seizures. Arch Neurol. 1976;33:322-325

54. Sato S, White BG, Penry JK, et al. Valproic acid versus ethosuximide in the treatment of absence seizures. Neurology. 1982;32:157-163.

55. Verrotti A, Cerminara C, Domizio S, et al. Levetiracetam in absence epilepsy. Dev Med Child Neurol. 2008;50:850-853.

56. Fattore $\mathrm{C}$, Boniver $\mathrm{C}$, Capovilla $\mathrm{G}$, et al. A multicenter, randomized, placebo-controlled trial of levetiracetam in children and adolescents with newly diagnosed absence epilepsy. Epilepsia. 2011;52:802-809.

57. Auvin S, Chhun S, Berquin P, Ponchel E, Delanoë C, Chiron C. Aggravation of absence seizure related to levetiracetam. Eur J Paediatr Neurol. 2011;15:508-511.

58. Cross JH. Topiramate monotherapy for childhood absence seizures: an open label pilot study. Seizure. 2002;11:406-410.

59. Piña-Garza JE, Schwarzman L, Wiegand F, Hulihan J. Pilot study of topiramate in childhood absence epilepsy. Acta Neurol Scand. 2011;123:54-59.

60. Yamauchi T, Aikawa H. Efficacy of zonisamide: our experience. Seizure 2004;13(Suppl 1):S41-S48.

61. Wilfong A, Schultz R. Zonisamide for absence seizures. Epilepsy Res. 2005;64:31-34.

62. Shahar EM, Brand N. Effect of add-on amantadine therapy for refractory absence epilepsy. J Pediatr. 1992;121(5 Pt 1):819-821.

63. Perry MS, Bailey LJ, Kotecha AC, Malik SI, Hernandez AW. Amantadine for the treatment of refractory absence seizures in children. Pediatr Neurol. 2012;46:243-245.
64. Lombroso CT, Forxythe I. A long-term follow-up of acetazolamide (diamox) in the treatment of epilepsy. Epilepsia. 1960;1:493-500.

65. Chao DH, Plumb RL. Diamox in epilepsy. A critical review of 178 case. J Pediatr. 1961;58:211-218.

66. Perucca E, Gram L, Avanzini G, Dulac O. Antiepileptic drugs as a cause of worsening seizures. Epilepsia. 1998;39:5-17.

67. Somerville ER. Some treatments cause seizure aggravation in idiopathic epilepsies (especially absence epilepsy). Epilepsia. 2009;50(Suppl 8): S31-S36.

68. Liu L, Zheng T, Morris MJ, et al. The mechanism of carbamazepine aggravation of absence seizures. J Pharmacol Exp Ther. 2006;319:790-798.

69. Zheng T, Clarke AL, Morris MJ, Reid CA, Petrou S, O’Brien TJ. Oxcarbazepine, not its active metabolite, potentiates GABAA activation and aggravates absence seizures. Epilepsia. 2009;50:83-87.

70. Snead OC 3rd, Hosey LC. Exacerbation of seizures in children by carbamazepine. N Engl J Med. 1985;313:916-921.

71. Horn CS, Ater SB, Hurst DL. Carbamazepine-exacerbated epilepsy in children and adolescents. Pediatr Neurol. 1986;2:340-345.

72. Talwar D, Arora MS, Sher PK. EEG changes and seizure exacerbation in young children treated with carbamazepine. Epilepsia. 1994;35: 1154-1159.

73. Coenen AM, Blezer EH, van Luijtelaar EL. Effects of the GABA-uptake inhibitor tiagabine on electroencephalogram, spike-wave discharges and behaviour of rats. Epilepsy Res. 1995;21:89-94.

74. Bouwman BM, Suffczynski P, Midzyanovskaya IS, Maris E, van den Broek PL, van Rijn CM. The effects of vigabatrin on spike and wave discharges in WAG/Rij rats. Epilepsy Res. 2007;76:34-40.

75. Parker AP, Agathonikou A, Robinson RO, Panayiotopoulos CP. Inappropriate use of carbamazepine and vigabatrin in typical absence seizures Dev Med Child Neurol. 1998;40:517-519.

76. Knake S, Hamer HM, Schomburg U, Oertel WH, Rosenow F. Tiagabineinduced absence status in idiopathic generalized epilepsy. Seizure. $1999 ; 8: 314-317$

77. Lortie A, Chiron C, Mumford J, Dulac O. The potential for increasing seizure frequency, relapse, and appearance of new seizure types with vigabatrin. Neurology. 1993;43(11 Suppl 5):S24-S27.

78. Yang MT, Lee WT, Chu LW, Shen YZ. Anti-epileptic drugs-induced de novo absence seizures. Brain Dev. 2003;25:51-56.

79. Schmidt D, Gram L, Brodie M, et al. Tiagabine in the treatment of epilepsy - a clinical review with a guide for the prescribing physician. Epilepsy Res. 2000;41:245-251.

80. Koepp MJ, Edwards M, Collins J, Farrel F, Smith S. Status epilepticus and tiagabine therapy revisited. Epilepsia. 2005;46:1625-1632.

81. Vinton A, Kornberg AJ, Cowley M, Matkovic Z, Kilpatrick C, O’Brien TJ. Tiagabine-induced generalised non convulsive status epilepticus in patients with lesional focal epilepsy. J Clin Neurosci. 2005;12:128-133.

82. Zhu Y, Vaughn BV. Non-convulsive status epilepticus induced by tiagabine in a patient with pseudoseizure. Seizure. 2002;11:57-59.

83. Genton P. When antiepileptic drugs aggravate epilepsy. Brain Dev. 2000;22:75-80.

84. Osorio I, Reed RC, Peltzer JN. Refractory idiopathic absence status epilepticus: A probable paradoxical effect of phenytoin and carbamazepine. Epilepsia. 2000;41:887-894.

85. Higgins GA, Breysse N, Undzys E, et al. Comparative study of five antiepileptic drugs on a translational cognitive measure in the rat: relationship to antiepileptic property. Psychopharmacology. 2010;207: 513-527.

86. Bialer M, Johannessen SI, Levy RH, Perucca E, Tomson T, White HS. Progress report on new antiepileptic drugs: A summary of the Eleventh Eilat Conference (EILAT XI). Epilepsy Res. 2013;103:2-30.

87. Large CH, Sokal DM, Nehlig A, et al. The spectrum of anticonvulsant efficacy of retigabine (ezogabine) in animal models: implications for clinical use. Epilepsia. 2012;53:425-436.

88. Trudeau V, Myers S, LaMoreaux L, Anhut H, Garofalo E, Ebersole J. Gabapentin in naive childhood absence epilepsy: results from two double-blind, placebo-controlled, multicenter studies. J Child Neurol. 1996;11:470-475. 
89. Arsov T, Mullen SA, Damiano JA, et al. Early onset absence epilepsy: 1 in 10 cases is caused by GLUT1 deficiency. Epilepsia. 2012;53: 204-207.

90. Nehlig A, Dufour F, Klinger M, Willing LB, Simpson IA, Vannucci SJ. The ketogenic diet has no effect on the expression of spike-and-wave discharges and nutrient transporters in genetic absence epilepsy rats from Strasbourg. J Neurochem. 2009;109(Suppl 1):S207-S213.

91. Groomes LB, Pyzik PL, Turner Z, Dorward JL, Goode VH, Kossoff EH. Do patients with absence epilepsy respond to ketogenic diets? J Child Neurol. 2011;26:160-165.

92. Dedeurwaerdere S, Vonck K, Claeys P, et al. Acute vagus nerve stimulation does not suppress spike and wave discharges in genetic absence epilepsy rats from Strasbourg. Epilepsy Res. 2004;59: 191-198.

93. Kostov H, Larsson PG, Røste GK. Is vagus nerve stimulation a treatment option for patients with drug-resistant idiopathic generalized epilepsy? Acta Neurol Scand Suppl. 2007;187:55-58.

94. Arya R, Greiner HM, LewisA, et al. Vagus nerve stimulation for medically refractory absence epilepsy. Seizure. 2013;22(4):267-270.

95. Kwan P, Johnson M, Merschhemke M, Lu S. Adjunctive brivaracetam in adults with uncontrolled generalized seizures: sub-population analysis of the results of a randomized, double-blind, placebo-controlled trial. Proceedings of the 64th annual meeting of the American Epilepsy Society. December 3-7, 2010; San Antonio, Texas. Abstract 1.267.

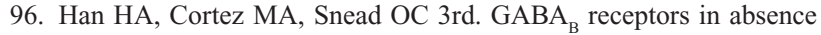
epilepsy. Epilepsia. 2010;51(Supp1 5):S24.

97. Ngomba RT, Santolini I, Salt TE, et al. Metabotropic glutamate receptors in the thalamocortical network: strategic targets for the treatment of absence epilepsy. Epilepsia. 2011;52:1211-1222.

98. Tringham E, Powell KL, Cain SM, et al. T-type calcium channel blockers that attenuate thalamic burst firing and suppress absence seizures. Sci Transl Med. 2012;4(121):121ra19.

99. Farwell JR, Dodrill CB, Batzel LW. Neuropsychological abilities of children with epilepsy. Epilepsia. 1985;26:395-400.

100. Blume WT. Lennox-Gastaut syndrome: potential mechanisms of cognitive regression. Ment Retard Dev Disabil Res Rev. 2004;10:150-153.

101. Shirasaka Y. Lack of neuronal damage in atypical absence status epilepticus. Epilepsia. 2002;43:1498-1501.

102. Chan KF, Jia Z, Murphy PA, Burnham WM, Cortez MA, Snead OC 3rd. Learning and memory impairment in rats with chronic atypical absence seizures. Exp Neurol. 2004;190:328-336.

103. Chan KF, Burnham WM, Jia Z, Cortez MA, Snead OC 3rd. GABAB receptor antagonism abolishes the learning impairments in rats with chronic atypical absence seizures. Eur J Pharmacol. 2006;541: 64-72.

104. Arzimanoglou A, French J, Blume WT, et al. Lennox-Gastaut syndrome: a consensus approach on diagnosis, assessment, management, and trial methodology. Lancet Neurol. 2009;8:82-93.

105. Beaumanoir A, Blume W. The Lennox-Gastaut syndrome. In: Epileptic Syndromes in Infancy, Chidhood and Adolescence. 5th ed. Roger J, Bureau M, Dravet C, Genton P, Tassinari CA, Wolf P, editors. London: John Libbey; 2005:89-114.

106. Motte J, Trevathan E, Arvidsson JF, Barrera MN, Mullens EL, Manasco P. Lamotrigine for generalized seizures associated with the LennoxGastaut syndrome. Lamictal Lennox-Gastaut Study Group. N Engl J Med. 1997;337:1807-1812.

107. Glauser T, Kluger G, Sachdeo R, Krauss G, Perdomo C, Arroyo S. Rufinamide for generalized seizures associated with Lennox-Gastaut syndrome. Neurology. 2008;70:1950-1958.

108. Schmidt D, Bourgeois B. A risk-benefit assessment of therapies for Lennox-Gastaut syndrome. Drug Saf. 2000;22:467-477.

109. Jeavons PM, Clark JE, Maheshwari MC. Treatment of generalized epilepsies of childhood and adolescence with sodium valproate (“epilim"). Dev Med Child Neurol. 1977;19:9-25.

110. Covanis A, Gupta AK, Jeavons PM. Sodium valproate: monotherapy and polytherapy. Epilepsia. 1982;23:693-720.

111. Tsuda Y, Oguni H, Sakauchi M, Osawa M. An electroclinical study of absence seizures in Dravet syndrome. Epilepsy Res. 2013;103: 88-96.
112. Ng YT, Conry JA, Drummond R, Stolle J, Weinberg MA; OV-1012 Study Investigators. Randomized, phase III study results of clobazam in Lennox-Gastaut syndrome. Neurology. 2011;77:1473-1481.

113. Donaldson JA, Glauser TA, Olberding LS. Lamotrigine adjunctive therapy in childhood epileptic encephalopathy (the Lennox Gastaut syndrome). Epilepsia. 1997;38:68-73.

114. Timmings PL, Richens A. Lamotrigine as an add-on drug in the management of Lennox-Gastaut syndrome. Eur Neurol. 1992;32:305-307.

115. Guerrini R, Dravet C, Genton P, Belmonte A, Kaminska A, Dulac O. Lamotrigine and seizure aggravation in severe myoclonic epilepsy. Epilepsia. 1998;39:508-512.

116. Sachdeo RC, Glauser TA, Ritter F, Reife R, Lim P, Pledger G. A doubleblind, randomized trial of topiramate in Lennox-Gastaut syndrome. Topiramate YL Study Group. Neurology. 1999;52:1882-1887.

117. De Los Reyes EC, Sharp GB, Williams JP, Hale SE. Levetiracetam in the treatment of Lennox-Gastaut syndrome. Pediatr Neurol. 2004;30: 254-256.

118. Huber B, Bömmel W, Hauser I, et al. Efficacy and tolerability of levetiracetam in patients with therapy-resistant epilepsy and learning disabilities. Seizure. 2004;13:168-175.

119. Farwell JR, Anderson GD, Kerr BM, Tor JA, Levy RH.Stiripentol in atypical absence seizures in children: an open trial. Epilepsia. 1993;34: 305-311.

120. Chiron C, Marchand MC, Tran A, et al. Stiripentol in severe myoclonic epilepsy in infancy: a randomised placebo-controlled syndromededicated trial. STICLO study group. Lancet. 2000;356:1638-1642.

121. Burdette DE, Sackellares JC. Felbamate pharmacology and use in epilepsy. Clin Neuropharmacol. 1994;17:389-402.

122. Jensen PK. Felbamate in the treatment of Lennox-Gastaut syndrome. Epilepsia. 1994;35(Suppl 5):S54-S57.

123. Lee YJ, Kang HC, Seo JH, Lee JS, Kim HD. Efficacy and tolerability of adjunctive therapy with zonisamide in childhood intractable epilepsy. Brain Dev. 2010;32:208-211.

124. Iinuma K, Haginoya, K. Clinical efficacy of zonisamide in childhood epilepsy after long-term treatment: a postmarketing, multi-institutional survey. Seizure. 2004;13(Suppl 1):S34-S39.

125. Lerman P. Seizures induced or aggravated by anticonvulsants. Epilepsia. 1986;27:706-710.

126. Vossler DG. Exacerbation of seizures in Lennox-Gastaut syndrome by gabapentin. Neurology. 1996;46:852-853.

127. Lemmon ME, Terao NN, NgYT, Reisig W, Rubenstein JE, Kossoff EH. Efficacy of the ketogenic diet in Lennox-Gastaut syndrome: a retrospective review of one institution's experience and summary of the literature. Dev Med Child Neurol. 2012;54:464-468.

128. Frost M, Gates J, Helmers SL, et al. Vagus nerve stimulation in children with refractory seizures associated with Lennox-Gastaut syndrome. Epilepsia. 2001;42:1148-1152.

129. Cersósimo RO, Bartuluchi M, Fortini S, Soraru A, Pomata H, Caraballo RH. Vagus nerve stimulation: effectiveness and tolerability in 64 paediatric patients with refractory epilepsies. Epileptic Disord. 2011;13:382-388.

130. Ferrie CD, Agathonikou A, Parker A, Robinson RO, Panayiotopoulos CP. The spectrum of childhood epilepsies with eyelid myoclonia. In: Duncan JS, Panayiotopoulos CP, editors. Eyelid Myoclonia with Absences. London:Libbey; 1996:39-48.

131. Striano P, Sofia V, Capovilla G, et al. A pilot trial of levetiracetam in eyelid myoclonia with absences (Jeavons syndrome). Epilepsia. 2008;49:425-430.

132. Wallace SJ. Myoclonus and epilepsy in childhood: a review of treatment with valproate, ethosuximide, lamotrigine and zonisamide. Epilepsy Res. 1998;29:147-154.

133. Manonmani V, Wallace SJ. Epilepsy with myoclonic absences. Arch Dis Child. 1994;70:288-290.

134. Labate A, Colosimo E, Gambardella A, Leggio U, Ambrosio R, Quattrone A. Levetiracetam in patients with generalised epilepsy and myoclonic seizures: an open label study. Seizure. 2006;15:214-218.

135. Häusler M, Kluger G, Nikanorova M. Epilepsy with myoclonic absences - favourable response to add-on rufinamide treatment in 3 cases. Neuropediatrics. 2011;42:28-29. 
Neuropsychiatric Disease and Treatment

Dovepress

\section{Publish your work in this journal}

Neuropsychiatric Disease and Treatment is an international, peerreviewed journal of clinical therapeutics and pharmacology focusing on concise rapid reporting of clinical or pre-clinical studies on a range of neuropsychiatric and neurological disorders. This journa is indexed on PubMed Central, the 'PsycINFO' database and CAS.

The manuscript management system is completely online and includes a very quick and fair peer-review system, which is all easy to use. Visit http://www.dovepress.com/testimonials.php to read real quotes from published authors.

Submit your manuscript here: http://www.dovepress.com/neuropsychiatric-disease-and-treatment-journal 